\title{
Pumping hydraulic systems and the use of an unloading valve in a hydraulic system
}

\author{
Kirill Kobzev ${ }^{1, *}$, Sergey Vyalov ${ }^{2}$, and Alexander Rybak ${ }^{1}$ \\ ${ }^{1}$ Don State Technical University, 1, Gagarina sq., 344003, Rostov-on-Don, Russia \\ ${ }^{2}$ Rostov State Transport University, 2, pl. Rostovskogo Strelkovogo polka, 344038, Rostov-on-Don, \\ Russia
}

\begin{abstract}
In order to identify the main functional capabilities of the control system of the pump-accumulator hydraulic power source equipped with a pump unloading machine of the proposed design, a numerical experiment was carried out. The experiment was a numerical solution of the above mathematical model of a power source. During the experiment, the influence of various structural parameters of the hydraulic pump unloading machine and the functional parameters of the power supply system as a whole on its dynamic properties was revealed. The article discusses the control system of a hydraulic power source of constant pressure, which is a pump-storage power source, equipped with the original design of the automatic unloading of the hydraulic pump, which provides relay switching of its operation mode. A mathematical model is proposed, obtained using a modeling technique based on the application of the theory of volumetric rigidity of hydraulic systems and their elements. The results of a numerical experiment carried out by numerically solving the equations that make up the mathematical model of a power source are also presented.
\end{abstract}

\section{Introduction}

Typically, in hydraulic systems, the oil temperature does not exceed $55^{\circ} \mathrm{C}$ and only in the simplest hydraulic drives, the stability of which is not high, can reach $70^{\circ} \mathrm{C}$. Maintaining the thermal regime of the hydraulic drive, in which there is significant power loss due to oil throttling, is a very difficult technical problem, requiring a significant increase in tank volume or the use of an effective artificial cooling system. In the latter case, we first waste power in the hydraulic drive, and then we spend additional power on the operation of the cooling system. Energy throttle control is similar to regulating the speed of a car with a brake when the gas pedal is fully depressed.

Given that at $\mathrm{p}=$ const, the power $\mathrm{N}$ is proportional to $\mathrm{Q}$ (or the speed of movement of the working body), which characterizes the ratio between the useful and lost power in the hydraulic drive described above. If with a quick supply (Qbp) the power losses are relatively small, then with a working feed (Qrp) almost all of the consumed power $\mathrm{N}$ is lost. The maximum losses, and therefore the maximum heating of the oil, occur when there is no

\footnotetext{
*Corresponding author: 5976765@mail.ru
} 
payload on the hydraulic motor, and with increasing load, the losses decrease and cooling conditions are facilitated, that is, the heating of the machine decreases with increasing load (in mechanical systems, vice versa).Hydraulic drive (hydraulic drive) - a set of devices designed to drive machines and mechanisms through hydraulic energy. Mandatory elements of a hydraulic drive are a pump and a hydraulic motor.

The hydraulic drive is a kind of "hydraulic insertion" between the drive motor and the load (machine or mechanism) and performs the same functions as a mechanical transmission (gearbox, belt drive, crank mechanism, etc.). The main purpose of the hydraulic drive, as well as mechanical transmission, is the conversion of the mechanical characteristics of the drive motor in accordance with the requirements of the load (conversion of the type of movement of the output link of the engine, its parameters, as well as regulation, protection against overloads, etc.). In general terms, the energy transfer in a hydraulic drive is as follows:

The drive motor transmits torque to the pump shaft, which reports the energy of the working fluid. The hydraulic fluid through the hydraulic lines through the control apparatus enters the hydraulic motor, where hydraulic energy is converted into mechanical energy.

After that, the hydraulic fluid returns either to the tank or directly to the pump via hydraulic lines.

Types of hydraulic drives

Hydraulic actuators can be of two types: hydrodynamic and volumetric:

In hydrodynamic drives, the kinetic energy of the fluid flow is mainly used.

Volumetric hydraulic drives use the potential energy of the pressure of the working fluid. Volumetric is a hydraulic machine, the working process of which is based on alternately filling the working chamber with liquid and forcing it out of the working chamber. Volumetric machines include, for example, piston pumps, axial piston, radial piston, gear hydraulic machines, etc. One of the features that distinguishes a volumetric hydraulic drive from a hydrodynamic one is high pressures in hydraulic systems. So, the nominal pressure in the hydraulic systems of excavators can reach $32 \mathrm{MPa}$, and in some cases the working pressure can be more than $300 \mathrm{MPa}$.

Volumetric hydraulic drive is used in mining and construction-road machines, in machine tools, etc. Depending on the design and type of elements included in the hydraulic transmission, volumetric hydraulic drives can be classified according to several criteria.

By the nature of the movement of the output link of the hydraulic motor.

Hydraulic drive when a hydraulic motor is used as a hydraulic motor, in which the driven link (shaft or housing) makes unlimited rotational motion;

Hydraulic drive of progress in which a hydraulic cylinder is used as a hydraulic motor an engine with the reciprocating movement of the driven link (piston rod, plunger or housing);

Swivel hydraulic drive when a rotary hydraulic motor is used as a hydraulic motor, in which the driven link (shaft or housing) makes a reciprocating motion at an angle less than $360^{\circ}$.

If possible regulation. If the speed of the output link (hydraulic cylinder, hydraulic motor) is regulated by changing the speed of the engine that drives the pump, then the hydraulic drive is considered unregulated. Adjustable hydraulic drive in which during its operation the speed of the output link of the hydraulic motor can be changed according to the required law. In turn, regulation can be: * throttle, volumetric, volumetric-throttle.

Regulation can be: manual or automatic.

Depending on the control tasks, the hydraulic drive can be: stabilized, programmatic, watching. Self-adjusting hydraulic drive automatically changes the fluid supply according to the actual needs of the hydraulic system in real time (without phase shift).

According to the scheme of circulation of the working fluid 
Closed circuit hydraulic actuator in which the working fluid from the hydraulic motor is returned to the suction pump hydraulic line. The hydraulic drive with closed circulation of the working fluid is compact, has a small mass and allows a high rotational speed of the pump rotor without the risk of cavitation, since in such a system the pressure in the suction line always exceeds atmospheric. The disadvantages include poor conditions for cooling the working fluid, as well as the need to lower the working fluid from the hydraulic system when replacing or repairing hydraulic equipment;
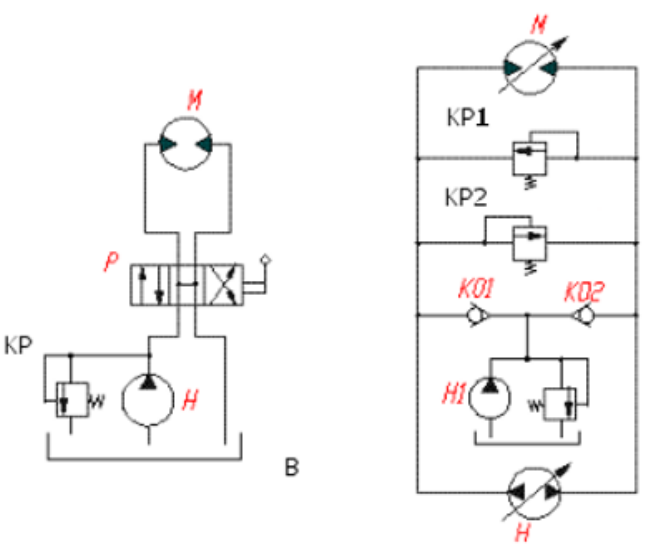

Fig. 1. Hydraulic systems.

Hydraulic systems with a closed circuit for the circulation of the working fluid (on the right) and with an open circuit (on the left). In the diagram on the left, the suction and drain hydraulic lines communicate with the tank (open circuit); in the diagram on the right, the tank is used only for auxiliary hydraulic systems (make-up systems). $\mathrm{H}$ and $\mathrm{H} 1$ are pumps; M - hydraulic motor; P - hydrodistributor; B - a hydraulic tank; H1 - make-up pump; KP1, $\mathrm{KP} 2$, - Safety valves; KO1 and KO2 - check valves. Safety valves KP (in the diagram on the left), KP1 and KP2 (in the diagram on the right) are triggered at a time when the load on the motor shaft is too high and the pressure in the hydraulic system exceeds the permissible value. Check valves $\mathrm{KO} 1$ and $\mathrm{KO} 2$ trigger.

Hydraulic power sources used in modern technological equipment and mobile machines are usually of two types - power sources for constant flow of working fluid and power sources for constant pressure. Among the constant pressure power sources, the most widely used are pump-accumulator hydraulic power sources, operating as follows. The working fluid from the flow source (pump) is supplied to the consumer, at the inlet of which a hydraulic accumulator is installed. When the consumer is operating, its power is supplied from the battery, in which the pump compensates for the loss of liquid and, thus, at the inlet to the consumer, the pressure is always maintained at the same level - equal to the pressure in the battery.

The disadvantage of such power sources is that when the consumer is not working, the battery is recharged and the safety valve opens, on which all the energy transmitted by the pump fluid is lost. In order to prevent the safety valve from tripping, the so-called relief valves [1] are used, which automatically open when the pressure at the pump outlet reaches the specified maximum (upper) value, ensuring idle operation. The consumer at this time works due to the energy stored in the battery. If the pressure in the accumulator drops below a predetermined minimum (lower) value, the discharge valve closes, putting the pump into operation.

Most of the currently known relief valves have significant dimensions and weight, are 
complex in design, but most importantly, as operating experience shows, they tend to freeze - stop the shut-off element in the intermediate position when the pressure in the hydraulic system and the pressure drop on the closing or opening shut-off valve are the same. In this case, throttling occurs on the shut-off element of the overflow valve, which leads to significant energy losses and heating of the working fluid.

\section{Methods}

The creation and design of hydraulic drives is connected with the fundamentals of the force interaction between a liquid and a solid and provides such advantages as: developed large forces and capacities with small dimensions, flexibility, simplicity and subtlety of regulation, protection against overloads, high reliability.

The fluid in the hydraulic press is used to transfer the energy generated by the drive to the working mechanism - the hydraulic cylinder. The use of liquid to transfer energy to a distance without the use of lever and other mechanical systems makes it possible to create hydraulic drives that are simple in design, which develop large working forces and have significant working displacements.

As a hydraulic drive, mainly high pressure plunger pumps and, in rare cases, multistage centrifugal pumps are used. In order to reduce the power of electric motors driving powerful high-speed hydraulic drives, high-pressure liquid accumulators (pump-battery drive) are used. In addition to pumps, for some types of drives, simple devices are also used - multipliers that work with steam, compressed air, an electric pump or an electromechanical transmission. In a hydraulic reciprocating drive, the full cycle of work is divided into idle, working and returning the actuator and the operation of auxiliary devices. Moreover, the indicated stroke of the hydraulic reciprocating drive can be carried out using various drives. Hydraulic drives for idling are often equipped with filling tanks with lowpressure liquid. Filling tanks are closed, the liquid in which is under the pressure of compressed air, or open, installed above the level of the working cylinder. Along with filling tanks, small cylinders and low pressure pumps are also used for idling.

\subsection{Non-accumulator pump drive}

The work developed by the pump corresponds to the useful work performed by the drive.

The non-accumulating pump drive has a high efficiency; its average value during the stroke in modern hydraulic drives is $0.6-0.8$. The pressure in the hydraulic system is precisely controlled. The ability to control the pressure can be used to control the actuator, that is, the maximum pressure in various periods of operation can be used as pulses for switching control equipment. The hydraulic system is not constantly under pressure, which facilitates the operation of the drive. It also has a relatively small size.

Along with the indicated advantages, a non-accumulator pump drive has the disadvantage that the power of the pumps with this drive is selected according to the maximum power of the driven mechanism. For mechanisms developing great efforts and operating at high speeds, the pump powers are excessively large. The pump motor power is also calculated from the maximum drive power, since with a non-accumulator pump drive mainly high-speed pumps are used, which are directly connected to the motor shaft. The operating speed of the actuator with a pump drive rarely exceeds $50 \mathrm{~mm} / \mathrm{s}$;

In hydraulic drives intended for certain technological operations, during the implementation of which the force increases sharply at the end of the stroke, and for the most part it remains much less than the maximum, it is advisable to use a variable-flow pump. 


\subsection{Battery-driven drive}

The presence of a battery in the hydraulic system changes the fundamental characteristic of the pump drive.

In hydraulic drives with a battery, the speed of the moving parts during the working stroke depends on the resistance it overcomes. The amount of energy consumed by the hydraulic actuator during the stroke depends on the stroke size and does not depend on the nature of the change in resistance, since it consumes a liquid of almost constant pressure. The efficiency of a hydraulic drive with a battery, taking into account fluid friction losses in the pipeline and in the controls, has an average value that is many times lower compared to a hydraulic drive with a non-accumulator pump drive. Its value is the lower, the less resistance the moving parts of the hydraulic drive overcome.

When there is no load, all the energy given off by the battery is spent mainly on overcoming the friction resistance of the liquid in the pipeline. Loss of energy due to deformation of the system (liquid, bed, etc.) is twice as much with a pump-accumulator drive compared with losses with a non-accumulator pump drive. Thus, the pumpaccumulator drive has significantly better speed characteristics compared to the pump drive, but at the same time, greater energy loss than that of the pump drive.

In this paper, we propose to consider a system for automatic control of a constant pressure power source equipped with a hydraulic pump unloading machine [2, 3], which contains a differential valve, which virtually eliminates the likelihood of the operation of the unloading machine in hovering mode. The article also provides information about the device of the proposed unloading machine, its mathematical model and the results of studies carried out in the form of a numerical experiment. The power supply circuit equipped with the proposed automatic unloading of the hydraulic pump is shown in Figure 2. Its operation is as follows. The working fluid from the hydraulic pump 1 through the check valve 2 is directed to the consumer. If the supply of the hydraulic pump is greater than the flow rate of the working fluid used by the consumer, then its excess is sent to the hydraulic accumulator 3 , the pressure of which rises. If the pressure at the inlet to the hydraulic accumulator 3 (pressure at point 2 of the hydraulic system) exceeds the setting pressure of the shutter of the regulator 10 of the unloading machine, then its shutter will move to the right and part of the working fluid will go to the control chamber 8 of the unloading machine, the pressure of which will increase, which will lead to moving the plunger 7 to the right and opening the shutter 5 of the drain line of the unloading machine, and therefore the working fluid from the pump under drain pressure through the channel 1-6-7-8-9 will go to the drain tank 4 - the hydraulic pump is unloaded.

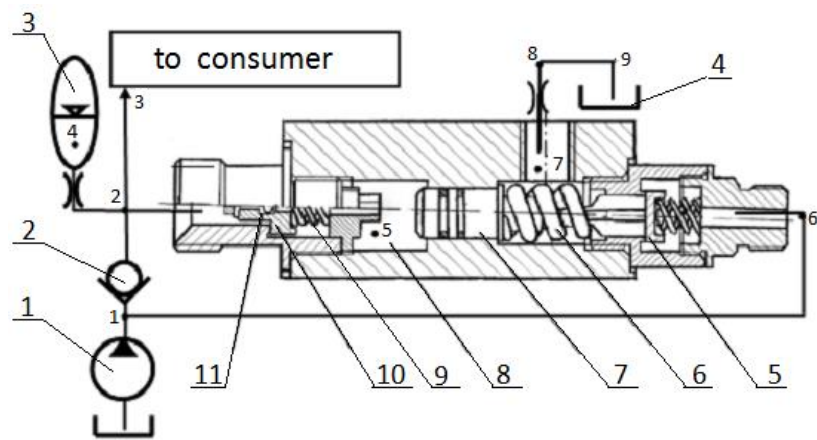

Fig. 2. Hydraulic diagram of a battery pack with automatic discharge.

The non-return valve 2 in this case will close and the consumer will only be supplied with the liquid in the hydraulic accumulator 3 . The pressure in the hydraulic accumulator 3 will decrease, which will lead to the outflow of the working fluid through the non-return valve 11 
from the control chamber 8 , and, accordingly, to close the shutter of the overflow valve 5 . The pump returns to operating mode.

The dynamics of the pump-accumulator power supply equipped with the proposed unloading machine can be represented by a system of differential equations describing the behavior of various elements of the system in the process of its transition from one stationary state to another. To describe the functioning of the hydraulic system of the power supply under unsteady conditions, we use a technique based on the concept of volumetric stiffness of the hydraulic system $[4,6,8,9-14]$, which makes it possible to calculate the behavior of the drive system in real time with subsequent analysis of its operational properties, identifying, the influence of design features and technological features of the system on its properties $[3,5,7]$. Mathematical models developed using the theory of volumetric rigidity greatly simplify and accelerate the analysis of hydraulic drive systems, which makes it possible to use the "partial synthesis method" in designing $[6,8]$, which greatly simplifies the design process and improves its quality.

\section{Results}

In order to identify the main functional capabilities of the control system of the pumpaccumulator hydraulic power source equipped with a pump unloading machine of the proposed design, a numerical experiment was carried out. The experiment was a numerical solution of the above mathematical model of a power source. During the experiment, the influence of various structural parameters of the hydraulic pump unloading machine and the functional parameters of the power supply system as a whole on its dynamic properties was revealed.

\section{Discussion}

The results showed that the functional properties of a power source equipped with an unloading machine are most affected by the force of the pre-compression of the working spring 6 , the outer diameter of the shutter of the regulator 10 and the diameter of the plunger 7 .

At the same time, a change in the force of pre-compression of the spring 6 and the diameter of the plunger 7 leads to a change in both the value of the upper pressure of the trigger of the unloading machine, and the difference between the upper and lower pressure of the trigger.

A change in the outer diameter of the shutter of the regulator 10 and a change in the force of the pre-compression of the spring of the shutter of the regulator 9 leads to a change in only the value of the upper operating pressure, leaving its lower value unchanged.

The main property of a power source with an automatic unloading device of the proposed design, confirmed as a result of a numerical experiment, is that the automatic unloading device provides a clear relay switching of the pump operation mode from unloading to operating mode and vice versa.

Thus, the proposed design of the hydraulic pump unloading machine ensures the operation of the pump-accumulator power supply of the hydraulic actuator in a given mode with a high degree of on and off accuracy at specified upper and lower pressure values. In order to set the response interval of the unloading machine and the value of the upper (lower) response pressure, it is most convenient to use the setting of the pre-compression force of the spring 6, as well as the shutter spring of the regulator 9, which can be adjusted during assembly, or create a regulator design with the ability to control these forces during operation of the machine unloading. 


\section{References}

1. A.T. Rybak, V.P. Zharov, A.V. Serdyukov, Russian Engineering Research 29(2), 194197 (2009)

2. A. Rybak, O. Lyakhnitskaya, MATEC Web of Conferences 132, 01001 (2017)

3. A.T. Rybak, A.R. Temirkanov, O.V. Lyakhnitskaya, Russian Engineering Research 38(9), $702-704$ (2018)

4. A.T. Rybak, A.R. Temirkanov, O.V. Lyakhnitskaya, Russian Engineering Research 38(3), 212-217 (2018)

5. K.O. Kobzev, S.A. Shamshura, A.N. Chukarin, V.P. Bogdanovich, V.E. Kasyanov, MATEC Web of Conferences 226, 01022 (2018)

6. K.O. Kobzev, S.A. Shamshura, A.N. Chukarin, A.I. Buryanov, V.E. Kasyanov, MATEC Web of Conferences 226, 01023 (2018)

7. K. Kobzev, A. Chukarin, IOP Conference Series: Earth and Environmental Science 403, 012145 (2019)

8. K.O. Kobzev, E.S. Bozhko, A.V. Mozgovoi, M.D. Molev, N.I. Stuzhenko, IOP Conference Series: Materials Science and Engineering 680, 012014 (2019)

9. K.O. Kobzev, E.S. Bozhko, A.V. Mozgovoi, E.I. Kostromina, L.G. Babenko, IOP Conference Series: Materials Science and Engineering 680, 012013 (2019)

10. I. Bartenev, P. Popikov, S. Malyukov, IOP Conference Series: Earth and Environmental Science 226(1), 012052 (2019)

11. P. Popikov, M. Drapalyuk, D. Druchinin, Lecture Notes in Mechanical Engineering, 595-608 (2020)

12. I. Chetverikova, P. Popikov, IOP Conference Series: Earth and Environmental Science 392(1), 012067 (2019)

13. M.V. Drapalyuk, P.I. Popikov, D.S. Stupnikov, S.V. Malyukov, IOP Conference Series: Earth and Environmental Science 392(1), 012057 (2019)

14. M.V. Drapalyuk, P.I. Popikov, R.V. Yudin, A.A. Fomin, R.V. Chernukhin, IOP Conference Series: Materials Science and Engineering 142(1), 012090 (2016) 